\title{
Controlled trial comparing two types of enteral nutrition in treatment of active Crohn's disease: elemental $v$ polymeric diet
}

\author{
D Rigaud, J Cosnes, Y Le Quintrec, E René , J P Gendre, M Mignon
}

\begin{abstract}
To determine whether an elemental diet or a polymeric defined formula diet would be more effective for treating active Crohn's disease, we conducted a prospective randomised clinical trial in 30 patients with active Crohn's disease unresponsive to steroids and/or complicated by malnutrition. They received a four to six week enteral nutrition course with either an elemental diet or a polymeric diet. Clinical remission occurred in 10 of the 15 patients on elemental diet compared with 11 of the 15 patients assigned to polymeric diet. Both groups showed similar improvements in nutritional status, biological inflammation, $\alpha_{1}$ antitrypsin clearance, and colonoscopic lesions (diminished in 17 out of 24 patients). Most patients relapsed during the year after discharge. We conclude that enteral nutrition, whatever the diet, is an efficient primary therapy for active Crohn's disease but does not influence the long term outcome.
\end{abstract}

Crohn's disease is a chronic disease characterised by recurrent acute attacks and remissions. Body weight loss and malnutrition are commonly recognised complications in patients with Crohn's disease. Nutritional support is often required during the course of the disease. As a first step, total parenteral nutrition has been used successfully as primary treatment in hopes of achieving both improvement of nutritional status and remission of the acute attacks. ${ }^{12}$ Considering the complications and difficulties of parenteral nutrition, enteral nutrition is a preferable method of nutritional support when possible. Some clinical experiences have shown that an elemental enteral diet (EED) is as effective as parenteral nutrition in inducing remission from active Crohn's disease. ${ }^{3-5}$ As stated by O'Morain et al, ${ }^{5}$ EED represents an alternative to total parenteral nutrition not only from a nutritional point of view but also because EED may induce a functional and antigenic bowel rest. Recently, the role of bowel rest was questioned by the studies of Greenberg $e t a l^{6}$ and Lochs $e t a l,{ }^{7}$ who both found rates of clinical remission during partial parenteral nutrition associated with oral foods given without restriction similar to those during total parenteral nutrition. These studies suggested that nonelemental diets may allow remission in many patients without additional drug therapy.

Since EED is not always available and is twice as expensive as polymeric defined formula diets (PFD), we compared the efficacy of both EED and PFD on the nutritional status, and on disease activity in patients with active Crohn's disease in a prospective randomised therapeutic trial in 30 patients.

\section{Methods}

\section{PATIENTS}

Thirty patients with Crohn's disease diagnosed by previously reported clinical, morphological, and pathological criteria ${ }^{8}$ participated in the study. The patients were randomly assigned to one of the two groups, EED or PFD, if no exclusion critera were noted. Fourteen patients were in Rothschild Hospital and 16 in Bichat Hospital. The characteristics of the patients are shown in Table I.

The criteria for inclusion were active Crohn's disease as assessed by a Crohn's disease activity index (CDAI $)^{9}$ greater than 150 , and an indication for nutritional support, i.e. clinical malnutrition, ${ }^{10}$ and/or failure to respond to steroids. Exclusion criteria were the following: gastric surgery of any type; large resection (greater than $100 \mathrm{~cm}$ ) of the small bowel; concomitant treatment with sulphasalazine or derivates, azathioprine, or a prednisolone dose higher than $20 \mathrm{mg} /$ day at the beginning of the study. Also excluded were patients with disease located in the upper digestive tract (including the jejunum), and patients with abdominal abscess, digestive fistulas, Crohn's disease activity index greater than 450 , or toxic megacolon. All patients gave informed consent. This study was approved by the ethical committee of Bichat Hospital.

TABLE I Main clinical characteristics of the 30 patients on elemental enteral diet (EED) and polymeric defined formula diet $(P F D)$ for acute Crohn's disease

\begin{tabular}{lcc}
\hline & $\begin{array}{c}E E D \\
(n=15)\end{array}$ & $\begin{array}{l}P F D \\
(n=15)\end{array}$ \\
\hline Age (years) & $33(10 \cdot 8)$ & $37 \cdot 2(11 \cdot 2)$ \\
Sex (M/F) & $9 / 6$ & $9 / 6$ \\
Disease duration (years) & $5 \cdot 9(3 \cdot 7)$ & $6 \cdot 8(6 \cdot 1)$ \\
Disease extent & 10 & 10 \\
$\quad$ Colon & 0 & 2 \\
$\quad$ Ileum & 5 & 3 \\
$\quad$ Ileocolon & 0 & 1 \\
Previous intestinal resection & 0 & 0 \\
$\quad$ ileocronic & 8 & 8 \\
Digestive fistula or abdominal mass & 5 & 4 \\
$\quad$ Clinical malnutriton & 2 & 3 \\
$\quad \begin{array}{l}\text { Steroid dependence } \\
\text { Steroid resistance }\end{array}$ & $4 \cdot 57(3 \cdot 4)$ & $4 \cdot 0(2 \cdot 7)$ \\
Prednisone cumulative dose during the & last 12 months (g/yr) & $86(10)$ \\
Body weight (\% IBW) & $84(13)$ & $239(67)$ \\
CDAI & $275(79)$ & \\
\hline
\end{tabular}

None of the differences were significant. IBW =ideal body weight. CDAI = Crohn's disease activity index. Age, duration, prednisolone dose, body weight and CDAI are expressed as mean (SD). 
EXPERIMENTAL DESIGN

Patients were randomised into EED or PFD groups according to random tables. The diet was administered through a nasogastric tube using a peristaltic pump and a cooling system. Foods and caloric drinks were not allowed during the study period. All medications were discontinued before the beginning of the study, except for prednisolone which was maintained at the same dose from day 0 to day 14 and then progressively tapered off. The median duration of the therapeutic period was 30 days ( $22-43$ days).

EED consisted of Vivonex $\mathrm{HN}$ in both hospitals and PFD consisted of Realmentyl in Rothschild hospital and of Nutrison in Bichat hospital. Energy and nitrogen input are given in Table II. These two latter diets have very similar composition with more than $95 \%$ long chain triglycerides as lipids, and glucose polymers (and no lactose) as carbohydrates. Nitrogen is provided as whole proteins from animal source (meat and egg in Realmentyl and casein in Nutrison).

\section{EVALUATION OF RESPONSE}

The following clinical, anthropometric, biochemical and endoscopic data were obtained throughout the study.

\section{Disease activity}

The activity of Crohn's disease was assessed weekly by the CDAI. ${ }^{9}$ Three-day faecal output was recorded on days -2 to 0,12 to 14 , and 26 to 28. Digestive $\alpha_{1}$ antitrypsin clearance (on three consecutive days' faecal outputs) and colonoscopy were performed before nutritional support and at the end of the therapeutic period in 24 patients. The $\alpha_{1}$ antitrypsin clearance was determined according to Bernier et al. "The endoscopists were unaware of the type of nutritional support. Only active lesions defined as informative according to Modigliani et $a l^{12}$ were taken into account. The findings of the second colonoscopy were compared to those of the first one, and five qualitative modalities of evolution were defined:

(1) Complete or almost complete improvement, i.e. disappearance of all ulcerations except a few aphtoid erosions or a few small superficial ulcerations.

TABLE II Characteristics of the elemental enteral diet (EED) and the polymeric defined formula diet (PFD) and details of energy and nitrogen inputs in the 30 patients with active Crohn's disease. Values, mean $(S D)$.

\begin{tabular}{lll}
\hline & $E E D$ & $P F D$ \\
\hline Energy content & $1 \mathrm{kcal} / \mathrm{ml}$ & $1 \mathrm{kcal} / \mathrm{ml}$ \\
Proteins & $18 \%$ & $18 \%(\mathrm{R}) ; 16 \%(\mathrm{~N})$ \\
Lipids & $0 \cdot 8 \%(\mathrm{~V})$ & $27 \%(\mathrm{R}) ; 36 \%(\mathrm{~N})$ \\
Carbohydrates & $81 \cdot 2 \%(\mathrm{~V})$ & $55 \%(\mathrm{R}) ; 48 \%(\mathrm{~N})$ \\
Duration of nutritional support (days) & $32(4)$ & $36(7)$ \\
Energy input & $2286(227)$ & $2311(304)$ \\
$\quad$ Absolute $(\mathrm{kcal} /$ day) & $154(19)$ & $154(16)$ \\
As \% EREE & $16 \cdot 2(1 \cdot 5)$ & $15 \cdot 6(1 \cdot 8)$ \\
Nitrogen input & $329(49)$ & $310(9 \cdot 2)$ \\
Absolute (g/day) & $49 \cdot 1(9 \cdot 3)$ & $51 \cdot 3(9 \cdot 2)$ \\
Ber kg body weight (mg/kg/day) & & \\
\hline
\end{tabular}

$\mathrm{V}=$ Vivonex $\mathrm{HN} ; \mathbf{R}=$ Realmentyl; $\mathrm{N}=$ Nutrison. $\mathrm{EREE}=$ estimated resting energy expenditure There was no significant difference between the two groups.
(2) Great improvement, i.e. disappearance of most of deep ulcerations and of at least $50 \%$ of superficial ulcerations.

(3) Slight improvement, i.e. indisputable improvement of acute lesions in some colonic segments or terminal ileum.

(4) No change.

(5) Worsening

Clinical remission was defined as a CDAI less than 150 during the last seven days. Trial was stopped if one of the following criteria was met: continuing the trial was hazardous for any reason; an increase in CDAI to a CDAI greater than 300 at day 14 or no other improvement in CDAI at day 21; the impossibility of obtaining daily caloric input greater than $1500 \mathrm{kcal}$ after the first three days or during three successive days at any point of the trial.

\section{Inflammatory assessment}

For each patient at $0,14,21$ and 28 days the following measurements were obtained using standardised automated techniques: sedimentation rate, $\alpha_{2}$ globulin level, and white blood cell count.

\section{Nutritional assessment}

For each patient at $0,14,21$ and 28 days the following data were obtained: body weight at $08.00 \mathrm{~h}$; triceps skinfold and arm circumference at the middle of the non-dominant arm; daily creatinine urinary output (three days each week) expressed as creatinine-height ratio; haemoglobin, albumin and transferrin blood levels.

\section{FOLLOW UP}

In all patients considered to have successfully undergone remission, an oral low fibre diet was reintroduced in normal amount in one to five days. Afterwards the patients were discharged from hospital without any treatment.

Each patient was maintained on symptomatic treatment alone, without corticosteroids, sulphasalazine or azathioprine, or any other known active treatment for Crohn's disease. Follow up included a visit one month after discharge with a prospective calculation of CDAI during the week before. A relapse was indicated by: a CDAI greater than 250, an increase in CDAI greater than 150 , the occurrence of complications, or the need for any active treatment including steroids, parenteral nutrition, or surgery.

\section{STATISTICAL ANALYSIS}

In order to obtain a larger number of patients, the study was performed in two centres. We analysed a centre effect for each comparison of the variables tested using analysis of variance with the centre as covariable. There were no significant effects of the centre in any of the results that follow. Hence their individual identities in the current study was not deemed critical, and no distinction between the two centres is made when presenting the results of EED $v$ PFD groups. 


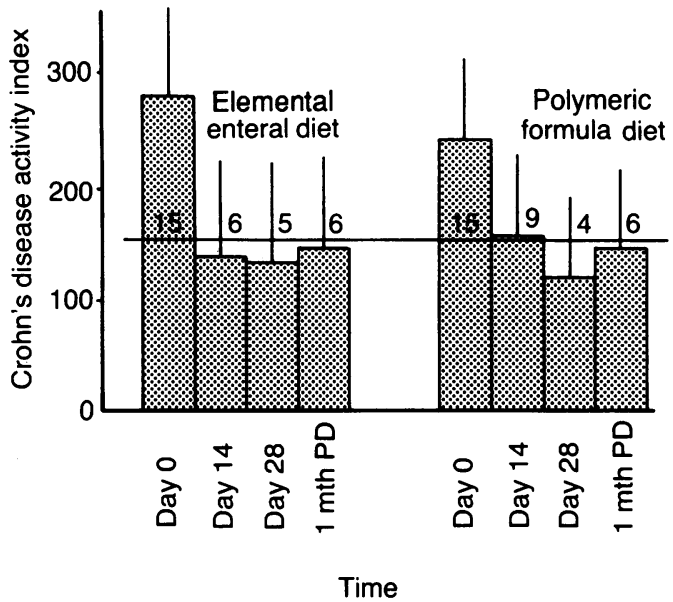

Figure 1: Mean (SD) values of the Crohn's disease activity index (CDAI) in the two groups (elemental enteral diet, polymeric defined formula diet) before (day 0$)$ and during enteral nutrition (day 14 and day 28) and one month after discharge $(P D)$. The numbers above the horizontal line indicate the numbers of patients with $C D A I>150$ at each time. The decrease of CDAI was significant $(p<0.05)$ in bot groups from day 14 on, without significant difference between the two groups.

All results are expressed as mean (SD). Significance of the differences between the two nutritional supports was determined by analysis of variance and analysis of covariance for all parametric variables. Differences in relapse rates between the two nutritional supports were checked by the Kaplan-Meier method. All these statistical analyses were performed using the MGLH module of Systat. ${ }^{13}$

\section{Results}

Thirty patients with active disease and mean (SD) CDAI of 257 (74) were admitted to the trial, 14 in Rothschild hospital and 16 in Bichat hospital. There was no significant difference between the two groups (EED and PFD) concerning age, sex, disease duration, prior complications or surgery, or prior one year cumulative prednisolone dose (Table I). Two patients in the PFD group had small bowel

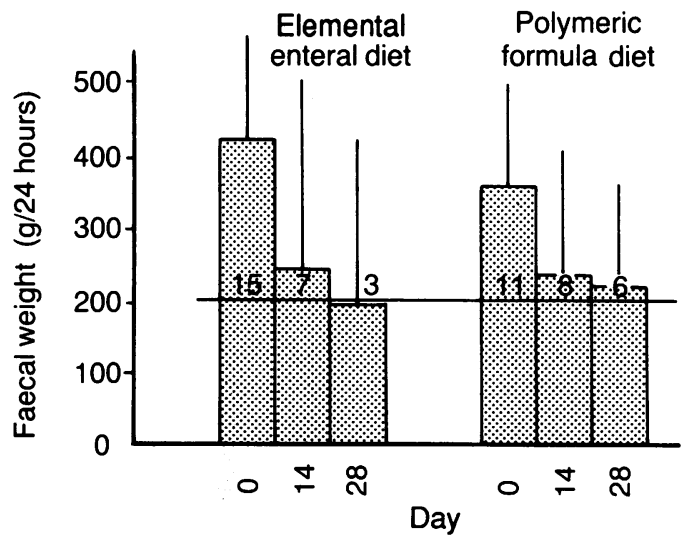

Figure 2: Mean (SD) values of the faecal weight in the two groups (elemental enteral diet, polymeric defined formula diet) before (day 0) and during enteral nutrition (day 14 and day 28). The numbers above the horizontal line indicate the numbers of patients with faecal output higher than $200 \mathrm{~g} / 24 \mathrm{~h}$ The decrease in faecal weight was significant $(p<0.05)$ in both groups from day 14 on, without significant difference between the two groups.
TABLE III Evolution of endoscopic lesions assessed by qualitative staging of active lesions in 24 patients who had colonoscopy at inclusion and at the end of the therapeutic period

\begin{tabular}{lcc}
\hline & $E E D$ & $P F D$ \\
\hline Total examinations & 11 & 13 \\
Improvement & 3 & 2 \\
Complete or almost complete & 3 & 4 \\
Great & 1 & 4 \\
Slight & 2 & 3 \\
No change & 2 & 0 \\
Worsening & & \\
\hline
\end{tabular}

Almost complete or complete improvement $=$ disappearance of all ulcerations except few erosions or small superficial ulcerations. Great improvement $=$ disappearance of most of deep ulcerations and of at least $50 \%$ of superficial ulcerations.

Slight improvement $=$ indisputable, but less than $50 \%$

Slight improvement $=$ indisputable, but less than $50 \%$
improvement of acute ulcerative lesions in some colonic segments.

lesions only. The mean CDAI at inclusion was not significantly different in the two groups: the mean (SD) CDAI for EED and PFD groups was 241 (68) and 254 (56) respectively in Bichat hospital, and 314 (77) and 244 (84) respectively in Rothschild hospital.

Fifteen patients received EED ( 8 in Bichat and 7 in Rothschild hospital) and 15 PFD (8 in Bichat and 7 in Rothschild hospital). None of the patients was excluded from the trial for inadequate inclusion criteria. All patients tolerated well the nutritional support, which was administered for at least 28 days in all patients, except one who deteriorated so that EED had to be stopped at day 22. ANOVA showing no centre effect, data from the two hospitals were pooled in the following section.

\section{DISEASE ACTIVITY}

Decrease in disease activity was demonstrated on both types of nutritional support by decreases in CDAI, faecal output, prednisolone dose, $\alpha_{1}$ antitrypsin clearance, and Crohn's disease endoscopic stage.

A CDAI of less than 150 was achieved in 16 out of the 30 patients $(53 \%)$ at day 14 , and 21 out of the 30 patients at day $28(70 \%)$. At day 28 , remission rates were equivalent among the two groups: 10 out of the 15 patients $(66 \%)$ in the EED group $v 11$ out of the 15 patients $(73 \%)$ in the PFD group had a CDAI less than 150 at day 28. As shown in Fig 1, the CDAI seemed to improve more rapidly on EED than on PFD, but the difference at day 14 was not significant $(p=0.07)$. On variance analysis, CDAI improvement was related neither to the location, the duration and the extent of the disease, nor to age and sex. The decrease in CDAI was independent on the CDAI at inclusion when the two groups were considered together $(p<0.05)$.

On entry 13 patients were taking $5-20 \mathrm{mg} /$ day prednisolone: seven in the EED group (mean $16.5 \mathrm{mg}$ ) and six in the PFD group (mean $14 \cdot 2 \mathrm{mg}$ ). Prednisolone was maintained at the same dose in three non-responding patients (two receiving EED and one receiving PFD). In the other 10 patients, prednisolone was tapered progressively from day 14 to one month after discharge. The daily dose of prednisolone was 0-10 mg at day 28 (mean $7.0 \mathrm{mg} /$ day in the five EED patients, and $6.5 \mathrm{mg} /$ day in the five PFD patients). 
TABLE IV Values of biological inflammatory markers, and clinical and biological nutritional markers before and after 28 days on nutritional support in both EED and PFD groups. Values, mean $(S D)$

\begin{tabular}{|c|c|c|c|c|}
\hline & \multicolumn{2}{|l|}{$E E D$} & \multicolumn{2}{|l|}{$P F D$} \\
\hline & Initial & Day 28 & Initial & Day 28 \\
\hline \multicolumn{5}{|l|}{ Inflammatory markers } \\
\hline Sedimentation rate & (42) 16 & $22(18)^{\star \star}$ & $38(17)$ & $26(25)^{\star \star}$ \\
\hline$\alpha_{2}$ globulins $(g / l)$ & $7.8(2 \cdot 0)$ & $6.8(1 \cdot 1)^{\star}$ & $7 \cdot 6(1 \cdot 8)$ & $6 \cdot 8(1 \cdot 7)^{\star}$ \\
\hline White blood cells $\left(10^{9} / 1\right)$ & $9 \cdot 8(3 \cdot 1)$ & $9 \cdot 1(2)$ & $10 \cdot 2(3 \cdot 7)$ & $8 \cdot 4(2 \cdot 4)^{\star}$ \\
\hline \multicolumn{5}{|l|}{ Nutritional markers } \\
\hline Body weight & $49 \cdot 2(9 \cdot 3)$ & $51 \cdot 0(9 \cdot 0)^{\star \star}$ & $51 \cdot 3(9 \cdot 2)$ & $53 \cdot 1(9 \cdot 1)^{\star \star}$ \\
\hline Triceps skinfold (mm) & $12 \cdot 6(6 \cdot 7)$ & $13 \cdot 3(6 \cdot 8)^{\star}$ & $13 \cdot 2(7 \cdot 4)$ & $14 \cdot 3(6 \cdot 6)^{\star}$ \\
\hline Mid-arm circumference $(\mathrm{cm})$ & $20 \cdot 9(2 \cdot 9)$ & $21 \cdot 1(2 \cdot 6)$ & $20 \cdot 8(3 \cdot 1)$ & $20.9(2.9)$ \\
\hline Creatinine-height index (\% normal) & $67 \cdot 8(13)$ & $75.9(18)^{\star \star}$ & $68 \cdot 8(14)$ & $76.9(14)^{\star \star}$ \\
\hline Haemoglobin $(\mathrm{g} / \mathrm{l})$ & $108(10)$ & $113(12)$ & $120(17)$ & $117(18)$ \\
\hline Albumin $(\mathrm{g} / \mathrm{l})$ & $32 \cdot 8(3 \cdot 8)$ & $35 \cdot 5(4 \cdot 4)^{\star \star}$ & $34 \cdot 1(2 \cdot 9)$ & $34 \cdot 7(2 \cdot 3)^{\star}$ \\
\hline Transferrin (mg/l) & $265(73)$ & $302(87)^{\star}$ & $260(66)$ & $288(58)^{\star}$ \\
\hline
\end{tabular}

$\mathrm{EED}=$ elemental enteral diet; PFD $=$ polymeric defined formula diet. ${ }^{\star} \mathrm{p}<0.05,{ }^{\star \star} \mathrm{p}<0.01$, and $\star \star \star \mathrm{p}<0.001$ versus initial values. There was no effect of the type of diet on the changes observed for these markers (variance analysis).
A dramatic decrease in faecal output was also observed early during both types of nutritional support: faecal output was 396 (147) g/day at inclusion $(\mathrm{n}=30), 232(233) \mathrm{g} /$ day at day $14(\mathrm{n}=$ $29)$, and $202(207) \mathrm{g} /$ day at day $28(\mathrm{n}=29)$ $(\mathrm{p}<0.001$ for day 14 and day $28 v$ day 0$)$. The decrease in faecal output was similar in the two groups (Fig 2).

Clearance of $\alpha_{1}$ antitrypsin showed a clear improvement through nutritional support in both groups $(p<0.01)$, without any significant difference between EED and PFD groups: from $104(65)$ to $56(79) \mathrm{ml} /$ day $(\mathrm{n}=12)$ in the EED group and from $50(26)$ to $31(25) \mathrm{ml} /$ day $(\mathrm{n}=12)$ in the PFD group.

The colonoscopic lesions also improved during nutritional support (Table III): 12 out of the 30 patients (40\%) clearly improved, six on EED group and six on PFD. This improvement was complete or almost complete in five out of the 24 patients $(21 \%)$ assessed qualitatively. No significant difference was shown between EED and PFD groups.

INFLAMMATORY ASSESSMENT

Table IV shows the values of the biological inflammatory markers before enteral nutrition

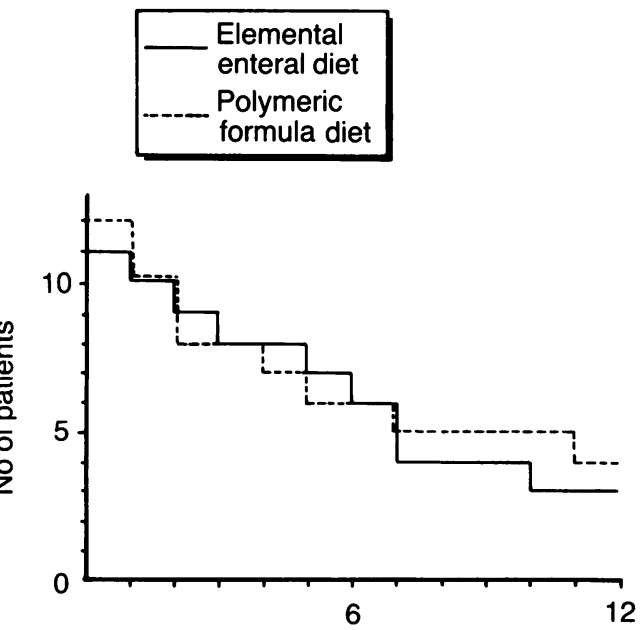

Time (months)

Figure 3: Number of patients without overt clinical relapse in each therapeutic group during the year after discharge. and at day 28 of EED and PFD. In all the 30 patients nutritional support induced a significant decrease in sedimentation rate at day 14 and day 28 , with mean values of 31 and 24 respectively, as compared to 40 before any nutritional support $(\mathrm{p}<0.05)$.

There was no difference between the two group (EED and PFD) for any of these inflammatory markers.

\section{NUTRITIONAL ASSESSMENT}

In both groups nutritional support induced a significant increase in some nutritional markers, i.e. body weight $(+1.83(1.8 \mathrm{~kg}))$ triceps skinfold $(+0.8(1 \cdot 1) \mathrm{mm})$, creatinine index $(+8(15) \%)$, and serum albumin $(+1.7(3.8) \mathrm{g} / \mathrm{l})$. The other markers did not change significantly. No difference between the two types of nutritional support was evident for any of these nutritional markers (Table IV).

\section{FOLLOW-UP}

At one month after discharge, 18 patients (nine in each group) had a CDAI less than 150, and five patients (two in EED and three in PFD group) had mild recurrent symptoms with a CDAI between 150 and 250 .

During the next 12 months an obvious clinical relapse (CDAI $>250)$, or a complication $(n=2)$ occurred in 16 out of the 23 patients (70\%). Two patients were treated surgically. There was no difference in the percentages of patients without obvious clinical relapse between the two groups (Fig 3).

\section{Discussion}

The present study confirmed that enteral nutrition may be used as the primary treatment and as supportive therapy in active Crohn's disease: enteral nutrition induced clinical remission in about two thirds of the patients. In most of them the clinical improvement was associated with reduced inflammation and evidence of endoscopic improvement.

A continuous line of evidence suggests a therapeutic role for nutritional support, i.e. parenteral or enteral nutrition, in patients with Crohn's disease, after failure of standard medical treatment, when surgical treatment is not desirable. In active Crohn's disease, total parenteral nutrition was shown to induce clinical remission in 57 to $83 \%$ of the patients. ${ }^{2} \mathrm{O}^{\prime}$ Morain et $a l^{5}$ found that an elemental diet was as effective as prednisolone in achieving clinical remission. Similarly, Saverymuttu et $a l^{14}$ and Lochs $e t a l^{4}$ found that an elemental diet, alone or associated with non-absorbable antibiotics, was successful in active Crohn's disease.

The present study confirms the efficacy of an elemental diet: EED induced a clinical remission $(\mathrm{CDAI}<150)$ in $66 \%$ of the patients after four weeks. (Fig 1). This remission was observed rapidly: at the end of the first two weeks, nine out of the 15 patients $(60 \%)$ reached clinical remission with a marked decrease in faecal output. As previously noticed by Logan et al, ${ }^{15}$ EED decreased the mean intestinal protein loss, 
as estimated here by the decrease in $\alpha_{1}$ antitrypsin clearance. In addition, a marked decrease in endoscopic active lesions was observed in six out of the 11 patients (54\%) at the end of the therapeutic period.

The proposed rationale for total parenteral nutrition as well as for elemental diet is that the associated bowel rest (i.e. no nutrient in the diseased bowel segment) should minimise motor functions and modify interactions between bacteria and bowel wall. But recent studies suggest that the efficacy of these nutritional supports was sustained by factors other than the so-called bowel rest. Lochs et $a l^{7}$ showed that parenteral nutrition plus oral foods (usual foods) was as efficacious as total parenteral nutrition and nil per os in inducing clinical remission in Crohn's disease. In the study of Greenberg et $a l^{6}$ 51 patients with active Crohn's disease unresponsive to medical management were allocated to three groups: total parenteral nutrition, partial parenteral nutrition with oral foods and enteral nutrition using PFD. Clinical remissions occurred in $71 \%, 60 \%$, and $58 \%$ respectively. Coyle and Sladen ${ }^{16}$ showed a $66 \%$ remission rate with PFD in mildly active Crohn's disease. In these two studies concomitant steroid treatment makes it difficult to relate the observed improvement to PFD alone.

The present study showed that PFD alone can induce remission of active Crohn's disease in up to three quarters of the patients. As in the comparative studies of Park et al, ${ }^{17}$ and of Raouf et $a l,{ }^{18}$ no significant difference was observed between the efficacy of PFD and EED. By contrast, Giaffer $e t a l^{19}$ found only a $36 \%$ response with PFD, significantly less than the $75 \%$ obtained with EED. However, this latter study selected patients only on the basis of the activity of their disease; malnutrition and lack of response to steroids were not criteria for inclusion. Above all, the clinical response to treatment was evaluated very early, after only 10 days of nutritional support. We showed that PFD was able to induce clinical remission in $73 \%$ of our patients evaluated after four weeks, and that with EED there was an improvement in exudative enteropathy. In addition, a marked decrease in endoscopic active lesions was observed in $46 \%$ of the patients. Finally, we observed on PFD an improvement in the inflammatory process, as documented by the decrease in sedimentation rate, white blood cell count and $\alpha_{2}$ globulin levels.

The design of the present study allows extensive comparisons between EED and PFD. It appears that EED may allow earlier clinical improvement and greater decrease in protein losing enteropathy than PFD. In the patients on EED the decrease in CDAI and faecal output was more pronounced than on PFD after two weeks. At the end of the therapeutic period the decrease in $\alpha_{1}$ antitrypsin clearance seems to be greater on EED than on PFD. Thus for these three variables we cannot exclude a beta type statistical error.

A clear improvement of both anthropometric and biological nutritional markers was obtained on the two diets, without any difference between the two. In patients with normal gastrointestinal functions, PFD has been reported to induce a nutritional repletion slightly better or identical to that induced by EED. ${ }^{20}$ In our study, the little advantage, if any, for EED over PFD concerning CDAI and exudative enteropathy was not large enough to induce different evolution of the nutritional status. This similiar improvement of nutritional status on the two diets, taken with the similar improvement of CDAI, suggest that in active Crohn's disease improvement of nutritional status ${ }^{21}$ may be a more important factor in the clinical remission obtained through total parenteral nutrition or enteral nutrition than total bowel rest or hypoallergenicity themselves.

The present study also demonstrates a clear improvement of endoscopic active lesions in 50\% of the patients, whatever the diet. This original finding allows us two assertions: (1) clinical improvement on nutritional support occurs in conjunction with morphological improvement, which is in agreement with the radiological improvement observed by Okada et $a l ;{ }^{22}$ and (2) in some patients there remain endoscopic active lesions at the end of the therapeutic period, despite indisputable clinical remission, as shown by Modigliani et al in patients treated by prednisolone. ${ }^{23}$ This possible persistence of endoscopic active lesions would partly explain the rapidity of clinical relapse in several patients.

Finally, our results confirm that enteral nutrition may be a possible treatment in patients with acute attacks of Crohn's disease and weight loss or malnutrition, when steroid treatment is impossible, undesirable or has failed. A four to five week period of treatment seems to achieve an acceptable rate of clinical and endoscopical remission. If clinical improvement is not apparent after 10 days, alternative or associated therapy is needed. The choice of EED or PFD, for a quite similar efficacy, is clearly dependent on the price of each diet: for example, in France, elemental diets are twice as expensive as defined formula diets. Alternatively, an elemental diet could be used as a shorter period. This should be determined by prospective evaluation.

1 Elson CO, Layden TJ, Nemchausky BAZ, Rosenberg JL, Rosenberg IH. An evaluation of total parenteral nutrition in the management of inflammatory bowel disesae. Dig Dis $S_{c i}$ 1980; 25: 42-7.

2 Muller JM, Keller HW, Erasmi H, Pichlmaier H. Tota parenteral nutrition as the sole therapy in Crohn's disease. A parenteral nutrition as the sole therapy in Croh
prospective study. Br f Surg 1983; 70: $40-43$.

3 Le Quintrec Y, Cosnes J, Le Quintrec M, Contou JF, Baumer $P$, Gendre JP, Bellanger J. L'alimentation entérale élémentaire exclusive au cours des formes corticorésistantes et corticodépendantes de la maladie de Crohn. Gastroentérol Clin Biol 1987; 11 : 477-82.

4 Lochs H, Egger-Schodle M, Schuh R, Meryn ST, Westphal G, Potzi R, Rhodes J. Is tube feeding with elemental diets primary therapy of Crohn's disease? Klin Wochenschr 1984 62: $821-5$

5 O'Morain C, Segal AW, Levi AJ. Elemental diet as primary treatment of acute Crohn's disease: a controlled trial. $B M \mathcal{F}$ 1984; 288: $1859-62$.

6 Greenberg GR, Fleming CR, Jeejeebhoy KN, Rosenberg IH Sales D, Tremaine WJ. Controlled trial of bowel rest and nutritional support in the management of Crohn's disease. Gutritional support in

7 Lochs H, Meryn S, Marosi L, Ferenci P, Hortnag H. Has total bowel rest a beneficial effect in the treatment of Crohn' disease? Clin Nutr 1983; $2: 61-4$.

8 Bernades P, Hecketsweiler P, Benozio M, et al. Proposition d'un systéme de critères pour le diagnostic des entérocolites inflammatoires et cryptogénétiques (maladie de Crohn et rectocolite hémorragique). Une étude coopérative du GREC. Gastroentérol Clin Biol 1978; 2: 1047-54.

9 Best WR, Becktel JM, Singleton JW. Rederived values of the eight coefficients of the Crohn's disease activity index (CDAI). Gastroenterology 1979; 77: 843-6.

10 Baker PB, Detsky AS, Wesson DE, et al. Nutritional assess- 
ment. A comparison of clinical judgment and objective measurements, $N$ Engl F Med 1982; 306: 969-72.

11 Bernier JJ, Florent C, Desmazures C, Aymes C, L'Hirondel C. Diagnosis of protein losing enteropathy by gastrointestinal clearance of alpha-1-antitrypsin. Lancet 1978; ii: 763-64.

2 Modigliani

findiani R, Mary JY. Reproducibility of colonoscopic findings in Crohn's disease: a prospective multicenter study

13 Wilkinson L. Systat, the system for statistics. Evanston IL: Systat Inc, 1987.

14 Saverymuttu S, Hodgson HJF, Chadwick VS. Controlled trial comparing prednisolone with an elemental diet plus nonabsorbable antibiotics in active Crohn's disease. Gut 1985; 26: 994-8.

15 Logan RFA, Gillon J, Ferrington C, Ferguson A. Reduction of gastrointestinal protein loss by elemental diet in Crohn's of gastrointestinal protein loss by elemental dis
disease of the small bowel. Gut $1981 ; 22: 383-7$.

16 Coyle BL, Sladen GE. Whole protein liquid diet in the treatment of acute uncomplicated Crohn's disease. $\mathcal{F ~ H u m}$ treatment of acute uncomp

17 Park RHR, Galloway A, Danesh BJZ, Russell RI. Double blind trial comparing elemental and polymeric diet as primary treatment for active Crohn's disease. Gut 1989; 30 A1453-4.

18 Raouf AH, Hildrey V, Rhodes JM. Controlled trial comparing a whole protein and an aminoacid based enteral feed as sole therapy for Crohn's disease. Gut 1989; 30: A729-30.

19 Giaffer MH, North G, Holdsworth CD. Controlled trial of polymeric versus elemental diet in treatment of active polymeric versus elemental diet in

20 Jones BJM, Lees R, Andrews J, Frost P, Silk DBA. Comparison of an elemental and polymeric enteral diet in patients with normal gastrointestinal function. Gut 1983; 24: 78-84

21 Harries AD, Danis VA, Heatley RV, Jones LA, Fifield R, Newcombe RG. Controlled trial of supplemental ora nutrition in Crohn's disease. Lancet 1983; i: 887-90.

22 Okada M, Yao T, Yamamoto $\mathrm{T}$, et al. Controlled tria comparing an elemental diet with prednisolone in the companing an eleme 1990; 37: 72-80.

23 Modigliani R, Mary JY, Simon JF, et al and the Groupe d'études thérapeutiques des affections inflammatoires digestives. Clinical, biological, and endoscopic picture of attacks of Crohn's disease. Evolution on prednisolone. Gastroenterology 1990; 98: 811-8. 